\title{
Conclusive evidence for a distinct congenital stationary night blindness locus in $\mathrm{Xp} 21.1$
}

\author{
Arthur A B Bergen, J B ten Brink, F Riemslag, E J M Schuurman, F Meire, \\ $\mathrm{N}$ Tijmes, $\mathrm{P} \mathrm{T}$ V $\mathrm{M}$ de Jong
}

\begin{abstract}
$\mathrm{X}$ linked congenital stationary night blindness (CSNBX) is a non-progressive retinal disorder characterised by decreased visual acuity and disturbance of night vision. CSNBX appears to be not only clinically but also genetically heterogeneous. On studying a single large family, we recently suggested the presence of a distinct locus for CSNBX in Xp21.1. Here, we describe the results of a linkage analysis in another large CSNBX family, which confirms this finding. Thus, the data presented here provide conclusive evidence for a distinct CSNBX locus in Xp21.1, closely linked to the $X$ linked retinitis pigmentosa type 3 gene. The results combined with other published results indicate the order XpterDXS451-DMD-DYS1-(DXS1110, CSNBX1,XLRP3)-DXS7-(CSNBX2, XLRP2)-DXS14-Xcen.

( $\mathcal{H}$ Med Genet 1996;33:869-872)
\end{abstract}

Department of The Netherlands Ophthalmic Research Institute, PO Box $12141,1100 \mathrm{AC}$

Amsterdam,

The Netherlands

A A B Bergen

J B ten Brink

F Riemslag

E J M Schuurman

$\mathrm{N}$ Tijmes

P T V M de Jong

Department of Ophthalmology, Academic Medical

Centre, Amsterdam,

The Netherlands

F Riemslag

Department of

Ophthalmology,

University of Gent,

Belgium

F Meire

Department of Epidemiology and Biostatistics, Erasmus University, Rotterdam,

The Netherlands

P T V M de Jong

Correspondence to: Dr Bergen.

Received 18 March 1996 Revised version accepted for publication 23 May 1996
Key words: genetic mapping; congenital stationary night blindness; X chromosome; linkage analysis.

Congenital stationary night blindness (CSNB) is a defect in night vision, which is present at birth. Night blindness may occur as a distinct genetic disease entity, or as part of more complex inherited disorders, among them retinitis pigmentosa.

Clinical and genetic heterogeneity has been suggested for both autosomal dominant and $\mathrm{X}$ linked CSNB (CSNBX). The clinical heterogeneity of CSNBX in patients, even within the same family, is the result of subtle variation of the involvement of rods or cones, or both, in the disease, which can be visualised through dark adaptation curves and electroretinogram (ERG) amplitudes. ${ }^{1-4}$ Three clinical forms of CSNBX have been distinguished: complete CSNB (CSNB1), incomplete CSNB (CSNB2), and Alland Island eye disease (AIED). CSNB1 is frequently associated with high myopia. We showed recently that the clinical expression of CSNB1 and CSNB2 appears not to correlate with distinct disease genes (Tijmes et al, manuscript submitted).

So far, three confirmed positions for CSNBX genes have been reported, all proximal to the reference locus DXS7 on proximal Xp. Multiple linkage studies have located a CSNBX gene to the chromosomal interval between DXS7 and DXS426, ${ }^{5-9}$ while another gene has been located even more proximal to the latter chromosomal interval. ${ }^{9}$ The localisation of the AIED gene has been refined to between DXS7 and DXS255. ${ }^{10-12}$

However, we recently suggested that yet another CSNBX gene may be located in Xp21.1, distal to the DXS7 reference locus. ${ }^{13}$ Here, we describe a linkage analysis in a new family with CSNBX, thereby providing conclusive evidence for a distinct CSNBX gene locus in $\mathrm{Xp} 21.1$.

\section{Subjects and methods}

CASES AND CONTROLS

Over the years, all members of pedigree P520 (fig 1) came to our department for ophthalmic diagnosis and genetic counselling. More recently, ophthalmic re-examination was performed, and blood was collected for DNA studies after informed consent. All pedigree members who took part in this study underwent an ophthalmological and electrophysiological examination.

Ophthalmological examination included best refracted visual acuity in both eyes, slit lamp examination, and direct and indirect fundoscopy in full mydriasis. Colour vision was examined with the Panel D-15 (unsaturated) and the Ishihara test. Affected males were examined by kinetic Goldmann perimetry using V-4-e, III-4-e, and I-4-e targets.

Flash ERGs were made, according to the ISCEV standard protocol, ${ }^{14}$ with a Ganzfeld dome. Recordings were made in mydriasis after 10 minutes dark adaptation in total darkness. The dark adaptation curves were obtained with a Goldmann Weekers adaptometer. After 10 minutes' light adaptation (3000 Lux), the threshold to a $15^{\circ}$ diameter square wave modulated field, at $11^{\circ}$ below the fixation mark, was determined in total darkness.

DNA AND LINKAGE ANALYSIS

Southern and PCR analyses were essentially carried out as previously described. ${ }^{1516}$ Details 


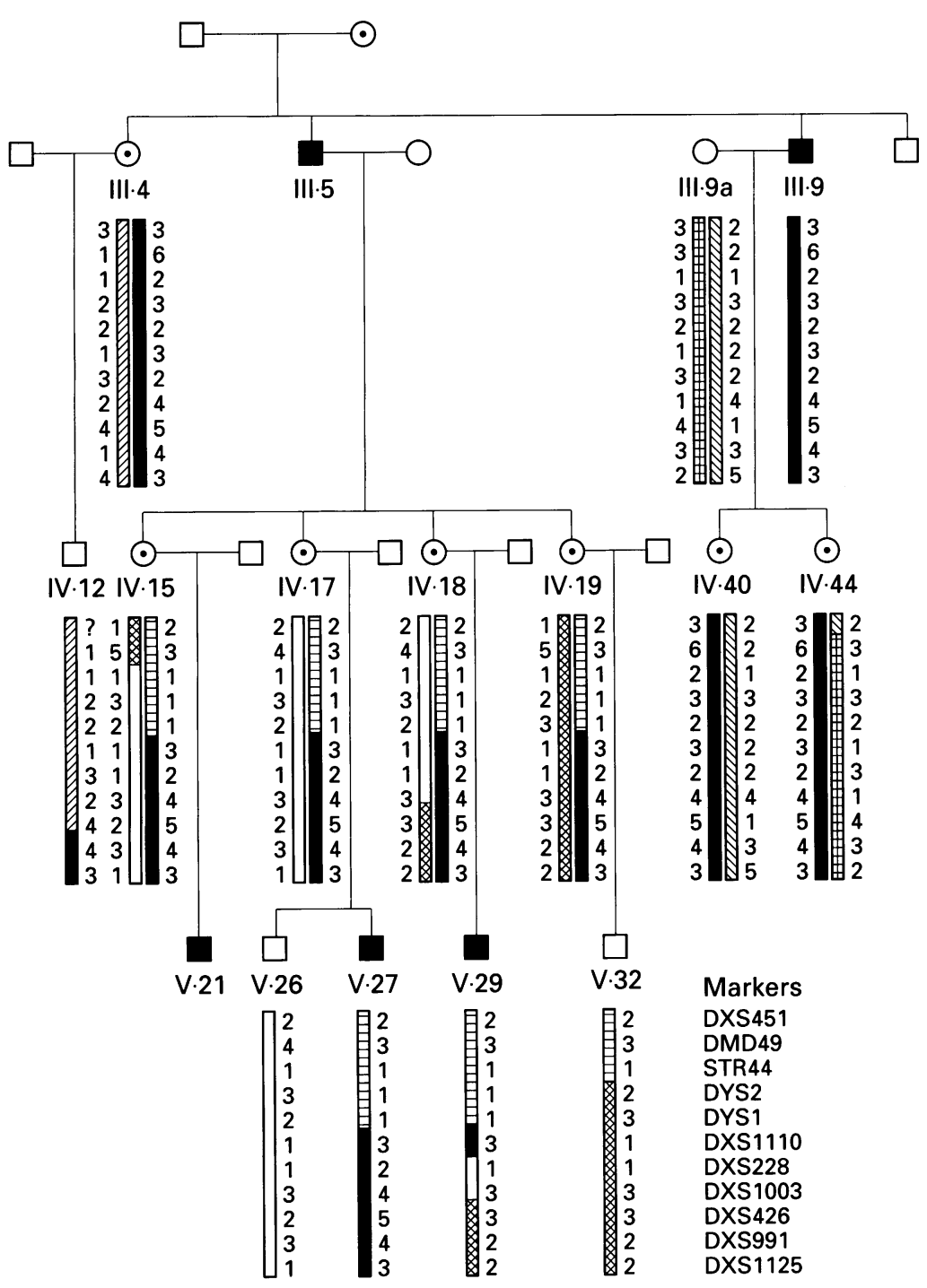

Figure 1 Haplotype analysis of pedigree P520.
From pedigree P520, five affected males (cases), seven obligate carriers, and three unaffected males (controls) were examined. The cases (aged from 16 to 64 years) had all experienced night blindness from very early childhood onwards. All had a reduced visual acuity which showed no deterioration during lifetime. All cases had myopia (ranging from S-3 to S9) and a fine horizontal nystagmus.

Fundoscopically, we did not find a pale optic disc, attenuated vessels, bone corpuscles, or retinal pigment epithelium changes in any of the affected males. Visual field tests showed no concentric narrowing or scotomas. Two patients had a slightly concentric restriction of their visual field. However, these patients did not have the field defects seen in retinitis pigmentosa, but a small restriction because of their high myopia $(-9)$. Colour vision was normal in all members of the pedigree examined.

None of the cases experienced deterioration, during an average follow up period of five years, of their visual acuity or ERG recordings. The ERGs of the patients seemed to lack any rod component, and showed the typical Schubert Bornschein "negative" wave shape, classifying all cases into the category of complete CSNBX. ${ }^{1}$ The cone ERG of all cases was not reduced in amplitude, but showed a slightly altered wave shape: the a wave was broader and the $b$ wave was reduced. Dark adaptation showed absence of a rod mediated branch.

The six obligate carriers and one possible carrier had a normal visual acuity, no myopia, and no abnormalities on ERG. The controls also had normal visual acuities and normal ERG. In conclusion, the data from these examinations strongly support the segregation of (complete) CSNBX in this family. Apart from the night blindness, as shown by the dark adaptation curves, there were no clinical or electrophysiological signs of retinitis pigmentosa.

concerning probes and primers used can be found in the Human Genome Database.

A CSNBX gene frequency of 0.0001 was used. Penetrance values for carriers were set to 0.00 . The primer sets for DYS1/DYS2, DXS1110/JL152, DXS228/DXS7/MAOB, DXS426/TIMP/SYN1, DXS991/ALAS2/ DXS14 represent loci which are physically very closely linked. Thus, for linkage analysis, each of these sets was considered to be one multiplex locus, yielding full informativity for every meiosis studied.

Linkage analysis was carried out with the LINKAGE computer program, version 5.03. In all multipoint applications, Haldane's mapping function was used. Multipoint calculations including all tested markers simultaneously were computationally too involved. Consequently, multipoint calculations were carried out with overlapping sets of three to four markers.

\section{Results}

CASES AND CONTROLS

The detailed clinical results of members of pedigree P23340 have been described elsewhere (Tijmes et al, manuscript submitted).

\section{DNA ANALYSIS}

The CSNBX family P520 was studied with 11 markers from proximal Xp. Very preliminary data on a few members of this family were reported by $\mathrm{Li}$ et $a{ }^{17}{ }^{17}$

Assuming the fewest number of recombinants, the most likely configuration of alleles is shown in fig 1 . Only one locus, DXS1110, cosegregated fully without recombination with the CSNBX gene in this pedigree. A recombination event between CSNB and the more proximally located loci DXS7/DXS228, DXS1003, DXS426, DXS991, and DXS1125 was shown by the haplotype of patient V.29. A recombination event between CSNBX and the more distally located markers DXS451, DMD49, DMD44, DYS2, and DYS1 could be inferred by comparing the combined haplotypes of IV.15, IV.17, IV.18, and IV.19 with the combined haplotypes of III.4 and III.9, given the assumption that the haplotype of patient III.5, if he had been studied, could possibly have shown a single recombination event. Thus, the most likely gene marker order by haplotype analysis is Xpter-DXS451-DMD-DYS1-(DXS1110, 
Table 1 Two point lod scores between CSNBX and a number of key loci in pedigrees P520 and P23340

\begin{tabular}{|c|c|c|c|c|c|c|}
\hline \multirow[b]{2}{*}{ Locus } & \multicolumn{6}{|l|}{$\theta$} \\
\hline & 0.0 & 0.01 & 0.05 & 0.1 & 0.2 & 0.3 \\
\hline DSX451 & $-x$ & -5.75 & -2.44 & -1.17 & -0.18 & 0.16 \\
\hline DMD & $-x$ & -2.00 & -0.16 & 0.43 & 0.67 & 0.54 \\
\hline DYS1 & $-x$ & 3.42 & 3.72 & 3.51 & 2.76 & 1.86 \\
\hline DXS1110 & 3.66 & 3.58 & 3.26 & 2.87 & 2.07 & 1.29 \\
\hline DXS7 & $-x$ & 1.26 & 2.27 & 2.38 & 1.98 & 1.33 \\
\hline $\mathrm{DXS} 1003$ & $-x$ & -0.42 & 1.31 & 1.73 & 1.66 & 1.19 \\
\hline DXS426 & $-x$ & -1.83 & -0.01 & 0.54 & 0.72 & 0.52 \\
\hline DXS14 & $-x$ & -3.43 & -0.88 & -0.01 & 0.49 & 0.46 \\
\hline
\end{tabular}

\section{CSNBX1,XLRP3)-DXS7-DXS1003- \\ DXS426-DXS991-DXS1125-Xcen.}

The results of the two point linkage analyses of pedigree P520 and pedigree P23430, which has previously been described by us, ${ }^{13}$ are presented in table 1 .

Multipoint lod scores were carried out with different sets of markers. Two of the most informative results are shown. The position of CSNBX was independently tested against the "key" loci DXS7 (fig 2) and DYS1 (fig 3) on a background map of loci flanking these loci.

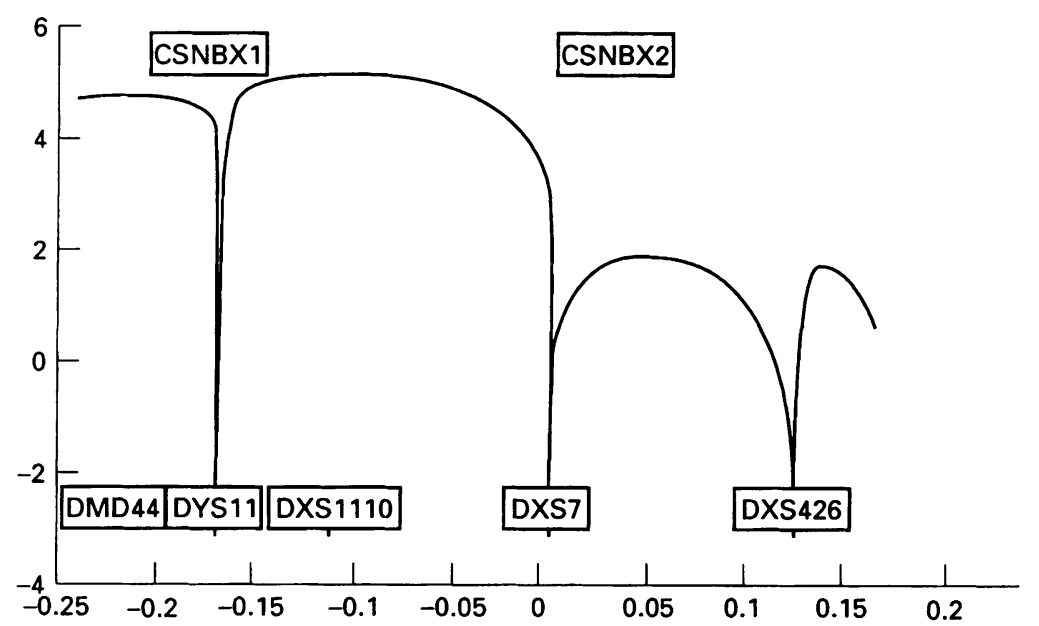

Figure 2 Multipoint linkage analysis of CSNBX relative to DXS7 (pedigrees P520 and P23340). Likelihoods of CSNBX defined by lod units (vertical axis) are shown with reference to a background genetic map in cM of DYSII, DXS7, and DXS426 (horizontal axis). The CSNBX gene is localised distal to DXS7.

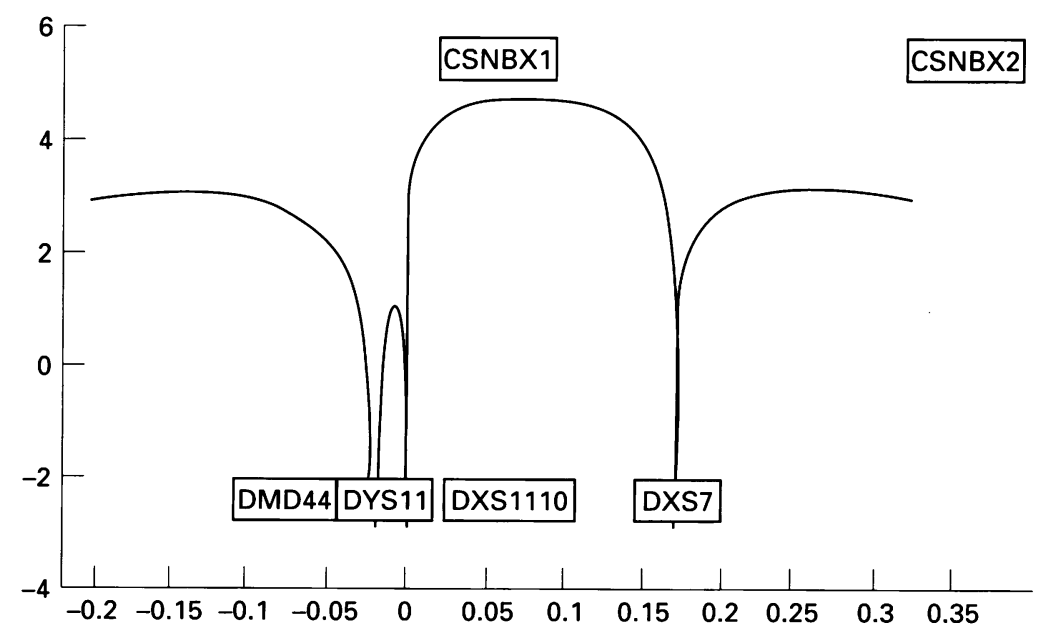

Figure 3 Multipoint linkage analysis of CSNBX relative to DYSII (pedigrees P520 and P23340). Likelihoods of CSNBX expressed in lod units (vertical axis) are shown with reference to a background map in cM of DMD44, DYSII, and DXS7 (horizontal axis). The CSNBX gene is most likely localised distal to between DYSII and DXS7.
The results shown in fig 2 indicate that the CSNBX gene in families P520 and P23430 is localised distal to DXS7, with a probability of more than 1000:1. Since the DYSII locus and CSNBX yielded highly significant two point lod scores (table 1), it was of interest to locate CSNBX relative to this locus as well. Fig 3 shows that CSNBX most likely is localised proximal to DYSII with a probability of at least 100:1. If DXS1110 was included in the analysis, multipoint lod scores favouring the interval DYSII-DXS228 as the most likely chromosomal region for CSNB exceeded 6.1, while other positions of CSNBX became even less likely.

\section{Discussion}

We previously suggested the presence of a distinct CSNBX gene in band $\mathrm{Xp} 21.1$ of the human $\mathrm{X}$ chromosome. ${ }^{13}$ However, that hypothesis was based on an observation in a single pedigree. A rare chromosomal rearrangement, a double crossover or another genetic mechanism leading to biased results in that pedigree, could not be excluded.

In this paper, we report a second family in which the CSNBX gene maps to $\mathrm{Xp21.1}$. Combining our results with our previously published Xp21.1 linked pedigree, we present here conclusive evidence for a second CSNBX locus on the short arm of the human X chromosome. Our data, combined with other published data, yield the chromosomal gene/marker order Xpter-DXS451-DMD-DYS1-(DXS1110, CSNBX1,XLRP3)-DXS7-(CSNBX2, XLRP2)-DXS14-Xcen.

Interestingly, the chromosomal positions of the CSNBX loci appear to coincide with those previously found for $X$ linked retinitis pigmentosa. ${ }^{1819}$ The latter finding provides further evidence for a functional relationship between RP and CSNB, and, in addition, may have important consequences for clinical investigation, gene mapping, and positional cloning studies of CSNBX and XLRP.

A functional relationship between CSNB and $R P$ was previously suggested by the finding that both CSNB and RP were shown to be caused by different DNA mutations in the rhodopsin gene (chromosome $3 q)^{20}$ as well as in the $B$ subunit of phosphodiesterase (chromosome $4 \mathrm{p}$ ). ${ }^{21}$ Our data suggest a positional relationship between CSNBX and XLRP and support that hypothesis.

From a clinical and functional point of view, it would be of interest to investigate whether CSNBX is truly stationary, or, at least in some patients, may be slightly progressive. It may be worth investigating the hypothesis that "incomplete" CSNB could develop into "complete" CSNB during a lifetime.

Genetic mapping of additional CSNBX families will probably provide information on the chromosomal position of XLRP genes as well. While the gene for XLRP type 3 has been very well localised, the position of the gene for XLRP type 2 has not yet been clearly established. ${ }^{18}$ Since XLRP type 2 is very rare, the genetic mapping of (additional) CSNBX families may be of crucial value in determining 
the genetic position of this disease gene on the proximal short arm of the $\mathrm{X}$ chromosome. Finally, in the course of positional cloning studies of XLRP or CSNBX genes, it may be well worth the effort to screen the DNA of both types of patients for subchromosomal deletions. Such aberrations have previously been proven to be of crucial value in the positional cloning process.

This study was supported by The Netherlands Society for Prevention of Blindness, and the Retinitis Pigmentosa Found ation of The Netherlands.

1 Miyake Y, Yagasaki K, Horiguchi M, Case Y, Kanda T Congenital stationary night blindness with negative electroretinogram. Arch Ophthalmol 1986;104:1013-20.

2 Schubert G, Bornschein H. Beitrag zur Analyse des Menschlichen Electroretinogram. Ophthalmologica 1952;123 396-413.

3 Khouri G, Ets MB, Smith VC, Wendell M, Pass AS. Xlinked congenital stationary night blindness: review and report of a family with hyperopia. Arch Ophthalmol 1988 . 106:1417-22.

4 Pearce WG, Reedyk M, Coupland SG. Variable expressivity in X-linked congenital stationary night blindness. Can $\mathcal{F}$ Ophthalmol 1990;25:3-10.

5 Musarella MA, Weleber RG, Murphey WH, et al. Assignment of the gene for complete congenital stationary signment of the gene for complete congenital stationary
night blindness (CSNB1) to Xp11.3. Genomics 1989;5: night blind

6 Gal A, Schinzel A, Orth U, et al. Gene of X-chromosomal congenital stationary night blindness is closely linked to DXS7 on Xp. Hum Genet 1989;81:315-18.

7 Bech-Hansen NT, Moore BJ, Pearce WG. Mapping a locu for X-linked congenital stationary night blindness (CSNB1) proximal to DXS7. Genomics 1992;12:409-11.

8 Aldred MA, Dry KL, Sharp DM, et al. Linkage analysis in $\mathrm{X}$-linked congenital stationary night blindness. Genomics 1992;14:99-104.

9 Bergen AAB, Kesteleyn P, Leys M, Meire F. Identification of a key recombinant which assigns the incomplete congenital
Stationary night blindn
Genet $1994 ; 31: 580-2$.

Alitalo T, Kruse TA, Forsius H, Eriksson AW, de la Chapelle A. Localization of the Aland island eye disease locus to the pericentromeric region of the human $\mathrm{X}$ chromosome by linkage analysis. Am f Hum Genet 1991;48:31-8.

11 Schwartz M, Rosenberg T. Aland island eye disease: linkage data. Genomics 1991;10:327-32.

12 Glass IA, Good P, Coleman MP, et al. Genetic mapping of a cone and rod dysfunction (AIED) to the proximal short arm of the human X chromosome. $\mathcal{F}$ Med Genet 1993;30: 1044-50.

13 Bergen AAB, ten Brink JB, Riemslag F, Schuurman EJM, Tijmes N. Localization of a novel X-linked congenital stationary nightblindness locus: close linkage to the RP3 type retinitis pigmentosa gene region. Hum Mol Genet 1995;4:931-5.

14 International Standardization Committee. Standard for clinical electroretinography. Arch Ophthalmol 1986;104:101320.

15 Bergen AAB, Samanns C, Schuurman EJM, et al. Multipoint linkage analysis in X-linked ocular albinism of the Nettleslinkage analysis in X-linked ocular albinism
hip-Falls type. Hum Genet 1991;88:162-6.

16 Bergen AAB, Wapenaar MC, Schuurman EJM, et al. Detection of a new submicroscopic deletion interval at the Norrie disease locus with a novel DNA probe isolated by ALU PCR fingerprint cloning. Cytogenet Cell Genet 1993; 62:231-5.

$17 \mathrm{Li} \mathrm{Y,} \mathrm{Bleeker-Wagemakers} \mathrm{EM,} \mathrm{Artlich} \mathrm{A,} \mathrm{et} \mathrm{al.} \mathrm{The} \mathrm{locus}$ for X-chromosomal congenital stationary night blindness is closely linked to TIMP in two families but not in a third one. Human Gene Mapping Workshop 11, London. Cytogenet Cell Genet 1991;58:2075A

18 Ott J, Bhattacharya SS, Chen JD, et al. Localizing multiple X chromosome linked retinitis pigmentosa loci using mul-
tilocus homogeneity tests. Proc Natl Acad Sci USA 1990; 87:701-4.

19 Bergen AAB, van den Born LI, Schuurman EJM, et al. Multipoint linkage analysis and homogeneity tests in 15 Dutch X-linked retinitis pigmentosa families. Ophthalmic Genet 1995;16:63-70.

20 Dryja TP, Berson EL, Rao VR, Oprian DD. Heterozygous missense mutation in the rhodopsin gene as a cause of congenital stationary nightblindness. Nature Genet 1993; 4:280-3.

21 Gal A, Orth U, Baehr W, Schwinger E, Rosenberg T Heterozygous missense mutation in the rod cGMP phospho-diesterase- $\beta$-subunit gene in autosomal dominant congenital stationary night blindness. Nature Genet 1994 4:280-3. 